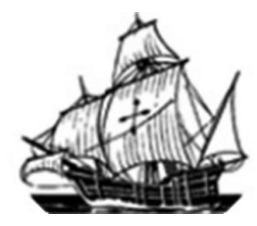

\title{
A ORALIDADE E SEUS ATUAIS CONTORNOS: PERFORMANCES E RECEPÇÕES DO CORPO NAS REDES SOCIAIS
}

\section{ORALITÉ ET SES CONTOURS ACTUELS: PERFORMANCES ET RÉCEPTIONS DU CORPS SUR LES RÉSEAUX SOCIAUX}

Taíse Alves Moreira ${ }^{1}$

\begin{abstract}
RESUMO
O presente artigo visa apresentar para a comunidade acadêmica como se desdobraria o processo de valorização simbólica nas redes sociais, devido à troca do contato físico pelo contato virtual, mesmo que o resultado de certas práticas (como o compartilhamento de conteúdo poético) resulte em sensações semelhantes a aquelas percebidas presencialmente. Observa-se o surgimento e a propagação das comunidades virtuais que apresentam uma proposta de aproximação de pessoas geograficamente separadas, mas que excluiria, em um primeiro momento, a prática de costumes orais. Embora proporcionem tais sensações, o ato da oralidade é adaptado nesse meio pelo processo da escrita. O questionamento é aberto quando se indaga sobre como se processariam as performances e recepções do corpo emanadas pela propagação da voz no contato presencial nesse mundo virtualizado que estaria provocando o isolamento das pessoas, inclusive daqueles participantes de grandes comunidades, que compartilham gostos, pensamentos e ideologias análogas. Assim, contarei com os seguintes objetivos específicos nesse processo inicial de investigação na pós-crítica: iniciar por uma leitura antropológica e/ou sociológica sobre cultura e estudos que trabalham sobre a valorização simbólica dos objetos, para situar a nova possibilidade de formatação social que envolve a coletividade denominada de comunidades virtuais. E na sequência, como a utilização desse dispositivo influenciaria sobre as performances e recepções do corpo visualizadas normalmente no contato presencial. Com um levantamento teórico consistente, composto por autores ímpares nos estudos aqui apontados, como Zumthor (2007 e 2010), Santaella (2003), Geertz (1989) e Thompson (1995), o trabalho ainda se encontra em fase inicial e, portanto não tem como foco apresentar novos conceitos, mas de reaplicá-los sob os novos acontecimentos culturais que envolvem o homem e a fala dentro de uma comunidade, mas que na contemporaneidade, se re-configura com uma maior utilização da escrita, em um espaço isolado existente no ambiente virtual, no que se refere a propagação de textos poéticos.
\end{abstract}

Palavras-chave: comunidades virtuais; oralidade; performance; recepção

\section{RÉSUMÉ}

Cet article vise à présenter à la communauté universitaire académique comment le processus de valorisation symbolique s'est déroulé dans les réseaux sociaux, en raison de l'échange de contacts physiques par le contact virtuel, même si le résultat de certaines pratiques (comme le partage de contenu poétique) se traduit par des

1Mestranda em Crítica Cultural pela UNEB - Universidade do Estado da Bahia, campus II Alagoinhas. Especialista em Administração Pública e bacharel em Administração de Empresas pela FSSS - Faculdade Santíssimo Sacramento, Alagoinhas-Ba. E-mail: taisealves23@gmail.com 
sensations similaires à ceux qui sont perçus par la présence. Nous observons l'émergence et la propagation des communautés virtuelles qui présentent une proposition d'approche des personnes séparées géographiquement par la distance mais qui exclurait la pratique des habitudes orales dans un premier temps. L'acte d'oralité qui est adapté à travers le processus d'écriture malgré la prestation de ces sensations. La question est ouverte quand on s'interroge sur la manière de poursuivre les représentations et les corps des réceptions émises par la propagation de la voix dans ce monde de présence physique virtualisée qui affecterait l'isolement des personnes, y compris ceux qui participent à de grandes communautés, qui partagent les goûts, les pensées et les idéologies analogues. Ainsi donc, je compterai avec les objectifs spécifiques suivants dans ce début du processus de recherche dans la post-critique: commencer par une lecture anthropologique et / ou sociologique sur la culture et les études qui travaillent sur la valorisation symbolique des objets, pour situer la nouvelle possibilité de la mise en forme qui implique la collectivité sociale appelée de communautés virtuelles. Et dans la séquence, l'utilisation de ce tel dispositif influencerait sur les performances et les réceptions du corps affichées normalement dans um contact présentiel. Avec les collections théoriques consistantes et cohérentes des auteurs dans les études ici indiquées comme Zumthor (2007 et 2010), Santaella (2003), Geertz (1989) et Thompson (1995), le travail est encore à un stade précoce et donc il $\mathrm{n}$ y a pas comme accent sur la présentation de nouveaux concepts, mais de les réappliquer dans les nouveaux événements culturels impliquant l'homme et la parole au sein d'une communauté, mais à l'époque contemporaine, de reconfigurer avec la plus grande utilisation de l'écriture dans un espace isolé en vigueur dans environnement virtuel en ce qui concerne la propagation des textes poétiques.

Mots-clés: Communautés virtuelles, oralité, performance et réception

\section{INTRODUÇÃO}

A história do amadurecimento do pensamento do homem e das relações que travou com o meio em que vive através do ato da oralidade, provavelmente proporcionaram aos estudiosos algumas dúvidas, reflexões, aceitações e contestações até chegarem a etnografias fidedignas ou mesmos a críticas contundentes quanto ao comportamento que presenciavam e dos contornos hoje observados com relação à empregabilidade dada ao processo da oralidade.

Com o advento dos avanços tecnológicos é atribuído aos novos equipamentos de comunicação uma dependência que implicaria nas relações sociais e culturais presencias. $\mathrm{O}$ ato da oralidade nesse momento fica reconfigurado a fim de se adaptar as propostas de aproximação que visam o encurtamento de distâncias geográficas, além de um maior contato entre as pessoas. Na pós-modernidade, o ganho de tempo se transformou no grande obstáculo a ser transponível para que se tenha cumprido as propostas trazidas pelo mercado consumidor e as redes sociais se apresentam como uma solução prática.

Nessa possibilidade de estudo dos modos de vida de comunidades urbanas, tal como dos novos valores que implicam nessas constituições culturais é presenciado o surgimento e a propagação das comunidades virtuais, que apresentam uma proposta de aproximação de pessoas geograficamente separadas, mas que excluiriam, em um primeiro momento, práticas orais. Embora proporcionem sensações semelhantes a aquelas presencialmente testemunhadas, o ato da oralidade é adaptado nesse meio pelo processo da escrita e da leitura.

Dessa forma, o foco proposto nesse trabalho ficará situado sobre como as valorizações 
simbólicas empregadas em determinadas ocasiões se tornaram tão fortes na sociedade atual, a qual demonstra que o status social é resultado do acumulo de riquezas do que pela compreensão e repasse de tradições orais desprovidas de sentidos.

Tal pensamento emerge em decorrência de leituras tanto no campo antropológico quanto dos estudos culturais que, mesmo apresentando posicionamentos distintos permitem reflexões acerca de mudanças culturais presenciadas na pós-modernidade. Dessa maneira se faz importante a contribuição de autores como Geertz, Thompson, Zumthor, Santaella dentre outros.

\section{NOÇÕES INICIAIS: CULTURA E ANTROPOLOGIA}

A sociedade como constituição social secularmente conhecida e descrita até os dias atuais representada por delimitações geográficas fixas a partir das características físicas e psicológicas dos habitantes, não pode mais ser concebida como um meio de transmissão conhecimento estática ou como único meio utilizado para a perpetuação da espécie humana. O pensamento de que o processo de evolução das capacidades do homem ocorria uniformemente em todas as culturas e que o evolucionismo e suas leis gerais aplicáveis a todo e qualquer lugar foi quebrado pela impossibilidade em explicar as similaridades existentes em locais distantes e incomunicáveis.

Por sorte, o pensamento científico levantou inquietações e empurrou filósofos, teórico e tantos outros estudiosos das áreas humanas, sociais e até exatas das suas zonas de conforto, de centros fincados em valores hierárquicos e religiosos e os levaram para as margens do ser. Isso, não afirma que rapidamente o homem despertou de uma cômoda situação para dar voz a outros, mas que quando foi aberto um caminho para o conhecimento do que estava intrínseco no "diferente" entendeu que o centro não era mais tão fascinante. Nesse momento, o trabalho de campo se mostrou interessante para o desenvolvimento das pesquisas.

Esse raciocínio descrito começou a perder o sentido e questionado a partir do pensamento de Sahlins (1979) quando coloca que Saussure debruçou-se no trabalho voltado para o papel dos signos da vida social e que Marx resumiu na objetivação do valor material das coisas. A contribuição de que o valor simbólico derivaria do valor de uso, também pode ser entendida sobre a vertente contrária, pois o valor de uso também era colocado a partir do valor simbólico. O antropólogo propõe o estudo no centro do mundo - no ocidente já que anteriormente, os estudos antropológicos ocorriam em comunidades primitivas a fim de melhor explicar o outro que se encontrava distante de suas concepções. 
Todavia é válido salientar que, os estudos construídos sob outros estudos possibilitaram uma revisitação de conceitos anteriormente qualificados como irrefutáveis, mas que agora se prestam a dialogar com novos pontos. Acreditando mais no meio como um produto do homem, o conceito de cultura defendido por Geertz (1989) mudou a forma de fazer e pensar a antropologia, quando exerce os trabalhos não mais como sendo um dos nativos da comunidade, mas a partir da compreensão das ações simbólicas que os habitantes praticavam; Geertz (1989, p. 37 e 38) argumentava que:

\footnotetext{
Nossa dupla tarefa é descobrir as estruturas conceptuais que informam os atos dos nossos sujeitos, o "dito" no discurso social, e construir um sistema de análise em cujos termos o que é genérico a essas estruturas, o que permanece a elas porque são o que são, se destacam contra outros determinantes do comportamento humano.
}

Entender que essas ações são dotadas de significações que envolvem uma esfera maior do que aqueles atos meramente descritos mostram que a descrição densa defendida pelo antropólogo estava na compreensão de que estaríamos diante de uma ciência interpretativa que visava enxergar que o homem vivia atrelado também por construções próprias.

Ampliando essas últimas considerações, mas não deixando de tecer criticas contundentes, o antropólogo John B. Thompson (1995) se interessa pela produção e transmissão de formas simbólicas através da comunicação de massa por entender que as formas simbólicas estão presentes a todo o momento na vida dos sujeitos. O processo da industrialização, do capitalismo e da mídia podem ser vistos como determinantes nas reformulações ocorridas do convívio em sociedade, o que implicaria nas conceituação acerca do que seja cultura.

As questões ideológicas se sobressaiam aos interesses descritos tecnicamente e com isso, o processo de valorizações simbólicas ficaria vinculado aos interesses de uma produção em massa de símbolos condicionados por contextos estruturados, como uma ideia de progresso semelhante a um referencial evolucionista.

Mesmo classificando a "Teoria Interpretativa da Cultura" como interessante por aplicar novos ares aos estudos antropológicos, através da interpretação dos fatos que geravam significados e permitiam observar os simbolismos como uma abordagem metodológica, Thompson apontou as fragilidades do trabalho do outro autor. Tomando por base a terceira crítica, a qual segundo Thompson (1995, p. 179) Geertz "dá atenção insuficiente aos problemas de conflito social e de poder" demonstrou que as relações existentes e interpretadas pelo método da descrição densa ficaram sintetizadas como estática, não compreendendo as 
dinamicidades que fluem dos contatos sociais, excluindo as múltiplas manifestações que ocorrem simultaneamente, em qualquer lugar e a todo o momento.

As relações de poder existentes e as intersecções por ela ocasionadas resultariam em tantas interpretações diferentes que deveriam constar no trabalho do pesquisador que envereda para esse campo de estudo. Para Thompson, Geertz apresentou o significado, mas não fez as correlações entre os outros significados desenvolvidos e que constam na cultura estudada. Thompson (1995, p.180) ratifica o posicionamento crítico a Geertz quando afirma que:

A concepção simbólica da Cultura, especialmente na forma elaborada nos escritos de Geertz, falha ao não dar suficiente atenção aos problemas de poder e conflito e, mais genericamente, aos contextos sociais estruturados dentro dos quais os fenômenos culturais são produzidos, transmitidos e recebidos.

O que fica evidente com Thompson é que as formas simbólicas estão presentes em contextos sociais estruturados recebidas por sujeitos que pertencem a contextos particulares e ao mesmo tempo coletivos resultando assim, em outras interpretações. São objetos que formam uma cadeia complexa de significações resultante de avaliações e conflitos e pelo próprio processo de valorização simbólica.

Isso começava a significar que, a vida do homem em sociedade não se resumiria mais a simples práticas de ações previsíveis e com resultados antecipados. Diferentemente, as formas simbólicas enquanto fenômenos sociais dotadas de valor necessitavam de um meio de transmissão como resposta ao alcance e produção de significações múltiplas. Na atualidade, os meios de comunicação mais modernos realizam essa função de repasse cultural de maneira ainda mais abrangente do que quando visualizadas nos estudos em comunidades pequenas e fechadas, longe do mundo ocidentalizado.

Esse autor apresenta ainda que o processo de produção e recepção das formas simbólicas requer análises que contemplem além de aspectos históricos, os de cunho espaçotemporais. Thompson (1995, p. 196) descreve que "as regras e convenções que dirigem muitas das ações e interações na vida social são implícitas, não formuladas, informais, imprecisas". Mas, ao acrescentar a esse posicionamento antropológico é questionado aos modernos meios de comunicação se as regras impostas para o manuseio e interação não trazem implícitas outras intenções.

Dessa forma, as condições sociais ultrapassariam as barreiras da limitação geográfica e se valeriam também da virtualidade para a disseminação dos aspectos culturais. Assim, a classificação de regras e convenções como esquemas flexíveis ganham ares atualizados sob as 
atuais aplicações. Thompson (1995, p. 200 e 201) resume que:

As várias características dos contextos sociais são constitutivas não apenas da ação e interação, mas, também, da produção e recepção de formas simbólicas. (...) A produção de formas simbólicas envolve o uso dos recursos disponíveis e a implementação de regras e esquemas de vários tipos por um ou mais indivíduos situados em determinada posição ou posições dentro de um campo ou instituição.

Após essa revisitação sucinta do pensamento de alguns antropólogos é válido acentuar que, as formas invisíveis de significação e simbolização também fazem parte do casting de trabalho do antropólogo, mas aqui as coloco de maneira a serem concebidas mais abertas e desamarradas de uma concepção de sociedade delimitada por espaços fronteiriços reduzidos.

De tal maneira é compreendido que, o crescimento da classe burguesa no início do século XIX foi determinante para a formação de novos conceitos sobre culturas, em decorrência da busca por ações e/ou produtos que impulsionam o homem a ter de maneira plena, uma vida em sociedade. O valor atribuído as coisas nem sempre são relacionadas ao valor de uso, mas ao simbólico. Sendo assim, o estudo sobre o termo cultura nos últimos tempos gira em torno de valores sociais baseados pelo consumo e daquilo que é tido como necessário para a explicação dessa palavra.

\section{UMA NOVA CONCEPÇÃO PARA O SIMBÓLICO}

As sociedades se desenvolveram ao mesmo tempo em que as formas de pensar dos indivíduos se libertaram do modelo clássico de enxergar a vida; o "crescimento" trazido pela expansão social também possibilitou novos estudos a fim de emergir os pensamentos culturais de outras comunidades que não apenas aquelas com representatividade no cenário mundial e consequentemente dos seus representantes.

Tais observações se desdobraram diante de estudos diacrônicos sobre culturas e das percepções dos autores (geralmente antropológicos) sob a realidade em que viveram durante a realização dos trabalhos de campo. Ao passo que esboçavam descrições etnográficas acerca das comunidades que estudavam, cada pesquisador foi elaborando teorias que se encaixavam para uma determinada comunidade. Todavia, a sociologia nasceu justamente para tentar explicar "as novidades" relacionadas a vida do homem em sociedade, diante das práticas sociais particulares que desempenhavam.

Ao abrir a porta para os estudos culturais, as narrativas, os testemunhos e os modos de vida se sobressaem dos meios obscurecidos e dão voz aos pertencentes de comunidades que 
não tinham representação, nem mesmo na literatura clássica. As análises de discursos também abriram espaço para uma nova forma de interpretar o homem no meio em que vive; uma etnografia da alma que não mais se deteria a fatores estéticos.

Mais contemporâneo, o antropólogo Kuper (2002) critica os estudos culturais, pois segundo o autor generalizam os conceitos abordados em um universo particular para explicar o global de maneira fechada (ideológica) sem permitir que os discursos sejam ampliados. Entende que o trabalho dos antropológicos perde espaço ao não abrir largamente, o leque de variáveis sociais passíveis de interpretações dentro de uma comunidade.

Todavia partir do particular para entender o global também pode se apresentar como um caminho interessante, pois problematiza sobre o perfil atual destacado pela sociedade ocidental com fundamentações capitalista: o consumo e o valor atribuído a esse conjunto de ações que envolvem a formação de processos culturais.

Com as políticas econômicas e sociais que permitiram a ascensão de maiorias periféricas ao mundo do consumo e ao consequente acesso daquilo que é exposto (para não dizer vendido) como sinônimo de status e classificação social mais elevado é que um número maior de pessoas deixou (ou tem a ilusão de deixar) a subalternidade e adentram em classes que viabilizam o poder de compra. Assim, as representações sociais passaram por mudanças significativas que desconstruíram estereótipos fixados em indivíduos eurocêntricos, dominadores ou dominados; esses modelos sociais pós-modernos incorporam atributos simbólicos que re-significados produzem valores distantes do conceito de cultura que segundo os estudos antropológicos se fundamentavam no repasse de valores produzidos nas comunidades.

Maria Elisa Cevasco (2003) ao referenciar Raymond Williams faz considerações sobre esses novos sentidos empregados a palavra cultura, a partir dos novos contornos materialistas no cenário social, devido principalmente pelo histórico de vida desse autor, originário da classe operária e com experiência esquerdista. Segundo Cevasco (2003, p. 23),

A diferença fundamental que a contribuição de Williams traz ao debate é a percepção materialista de cultura: os bens culturais são resultado de meios também eles materiais de produção (indo desde a linguagem como consciência prática aos meios eletrônicos de comunicação), que concretizam relações socais complexas envolvendo instituições, convenções e formas. Definir cultura é pronunciar-se sobre o significado de um modo de vida.

Enfatiza que as transformações ocorridas a partir de 1960 desencadeadas pelo uso cada 
vez mais frenético dos meios de comunicação de massa potencializaram a luta pela elevação das culturas e das suas particularidades com as diferenças culturais. Tal resultado visualizado se coloca como contrário ao discurso universalizador anteriormente propagado.

Os estudos de Jacques Derrida se voltaram para a desconstrução de sentidos fixados para o termo cultura; ao invés da construção de sentidos ou da interpretação de descrições afim da obtenção de novo significados, Derrida (2001) apresenta críticas com relação à noção de sentido, amparado pelo material de Saussure. Tais críticas se referem a necessidade de quebra de sentidos fixados, visto que segundo ele, não existem sentidos plenos, devido a ocorrência de multiplicidades, outras conotações também empregadas à sentidos primários.

Diante dessas colocações é percebido que o olhar do antropólogo sobre as relações de poder conceitua e/ou delimita a possibilidade de estudos de outros significados dentro de uma sociedade. Hoje, a comida, a roupa, e também as redes sociais tem valores de uso como forma de valor simbólico voltados para um determinado status social; os críticos culturais como apresentados acima perceberam que as ações sociais são re-significadas propiciando o pensamento de que o aumento do consumo desemboca em sensação de pertencimento a determinado grupo.

Com a presença dos autores acima e suas respectivas linhas de pensamento é possível convergir para uma noção de cultura como a nomeação de algo como força vital para a perpetuação de um grupo sob normas e condutas regulamentares. A constituição de símbolos foi e continua sendo o umbigo das pesquisas antropológicas e dos estudos culturais que reconhecem nessas tradições, elos de interseção que as mantém vivas por longos períodos até que influências externas movam as estruturas formadas, visto que a pós-modernidade acelera esse processo de trocas simbólicas culturais.

Assim, o sujeito emergente desse processo de subjetivação nasce pluralizado por conceitos que atendem a outros interesses líquidos que não apenas aqueles que supririam primariamente, as necessidades básicas do ser. Também é possível pensar que através de alguns dispositivos possamos enxergar além daquilo que colocamos como estáticos. Um poema, por exemplo, quando sai da esfera escrita e segue pela ritmicidade, sincronia e ondulações da voz ganha outros contornos quando expostos nas redes sociais mesmo se proliferando com objetivos diversos ou alheios a essas propostas.

$\mathrm{Na}$ contemporaneidade, as relações interpessoais se submetem aos dispositivos de controle definidos por Agamben (2009, p.40) como "qualquer coisa que tenha de algum modo a capacidade de capturar, orientar, determinar, interceptar, modelar, controlar e assegurar os 
gestos, as condutas, as opiniões e os discursos dos seres viventes" que, por sua vez vigiariam esses imbricamentos para observações de como ocorrem essas uniões interpessoais. Essas contribuições permitem reflexões no que se refere aos símbolos que encontramos em uma sociedade de base capitalista.

\section{A ORALIDADE: NOVOS CONTORNOS}

Foi visto até então que, o processo de valorização simbólica já se desenvolve desde que o homem mantém relações sociais com outros indivíduos; a alocação de significações aos atributos escolhidos como forma de representação local tende a caracterizar determinada cultura, como uma imagem criada para a identificação daquele espaço.

Através da comunicação oral muitos desses símbolos ganharam força e foram repassados para gerações seguintes; isso em decorrência da potencialidade característica da voz humana que estabelece sentidos e autoridade permitindo o nascimento de performances e recepções no corpo de quem as profere e em quem as escuta.

É entendido que, o repasse das tradições culturais necessita de um caminho, um meio para a difusão do conhecimento adquirido, a partir das relações interpessoais constituídas; esse canal viabiliza o processo de valorizações simbólicas a fim de que atinja uma amplitude maior. Entretanto, proporcionalmente ao aumento do número de sujeitos que tem contato com determinada cultura, não é obtido necessariamente como resultado, o crescimento na valorização dos objetos escolhidos como representantes simbólicos. Para Pierce (1931, apud SANTAELLA, 2012, p.133):

o símbolo é um signo que se conecta com seu objeto por meio de uma convenção de que ele será assim entendido ou, ainda, por meio de um instinto ou ato intelectual que o toma como representando seu objeto, sem que qualquer ação necessariamente ocorra para estabelecer uma conexão factual entre o signo e objeto.

É pela voz que o sujeito enquanto ser representante ou não de determinado grupo social tem a oportunidade de concordar ou discordar sobre os fatos ocorridos assim como tem o livre arbítrio para decidir se repassa os conhecimentos que possui ou cessa a transmissão de saberes; dessa maneira, a voz se mostra como o melhor e o mais utilizado meio para a propagação dos símbolos produzidos com a finalidade de conexão entre as partes envolvidas.

A oralidade se apresenta de tal maneira que não necessita de maiores explicações para sua aplicabilidade; se não possui nenhum problema físico que o impeça de falar, o homem simplesmente fala completando um ciclo da comunicação que começa pela emissão, 
processamento, recepção e realimentação da mensagem, pois através da propagação de um discurso produz sentidos compostos por vários outros significados.

A carga semântica que a linguagem carrega e que vinculada a outras capacidades da voz em frases com entonações e ritmos diversos resulta no contato presencial em performances e recepções. No que se refere a esse termo Zumthor (2007 [1915]) mesmo há quase de 100 anos atrás das atuais configurações encontradas na nossa sociedade já presenciava as alterações sociais e alegava que estávamos numa era, na qual formas de transmissão oral se diferenciavam das tradicionais, no que tange a prospecção que o corpo emana.

Mas, na pós-modernidade presenciamos cada vez mais intensificada, a migração dos relacionamentos interpessoais para o cyber espaço a partir de uma proposta de aproximação entre sujeitos, independente de pertencerem ou não a grupos com ideais semelhantes na vida real. As redes sociais como dispositivos de poder (Agamben, 2009) fazem o papel de intermediação proposital, no qual é possível visualizar e compartilhar ações e/ou objetos dotados por uma carga simbólica que influenciariam sobre as performances e recepções do corpo visualizadas normalmente no contato presencial.

$\mathrm{O}$ ato da oralidade é adaptado nesse espaço digital pelo processo da escrita: o questionamento é aberto quando se indaga sobre como se processariam as performances e recepções do corpo (Zumthor, 2007) emanadas pela propagação da voz no contato presencial, nesse mundo virtualizado, sustentado por valorizações outras que movimentam as escolhas, os desejos e as formas de comunicação. Já os textos poéticos como referenciais simbólicos compostos por infinitas significações, nos dias atuais ganham um fôlego considerável, ao serem largamente compartilhados nas redes sociais virtuais, dentro de uma cultura de massa com características fomentadas por uma indústria cultural. Mas vale ressaltar que, a troca entre pessoas separadas por longas distâncias, de textos com essas características já ocorre desde quando o homem desenvolveu os primeiros meios de comunicação.

Assim, "a geração atual" mantém relações interpessoais amparadas pelos recursos tecnológicos e trocam esse tipo de conteúdo poético em algumas situações, em substituição do contato presencial sustentado pela oralidade, implicando em novos modos de vida substanciados por uma cultura de massas ${ }^{2}$. Nesse ínterim, as relações presenciais sofreram

2 Santaella (2003, p.52 e 53) traz uma diferenciação nomenclatura cultura de massas e da cultura das mídias na qual: "Cultura das mídias, procurava dar conta de fenômenos emergentes e novos na dinâmica cultural quer dizer, o surgimento de processos culturais distintos da lógica que era própria da cultura de massas. Contrariamente a esta que é essencialmente produzida por poucos e consumida por uma massa que não tem poder para interferir nos produtos simbólicos que consome". 
alterações contundentes, mas o processo da comunicação entre os humanos não deixou de existir em razão de uma troca ambiental. Todavia, a voz não é mais ouvida, tão pouco as vibrações produzidas são percebidas pelo corpo; as performances resultam das interpretações constituídas pelo processo da leitura e não mais da escuta, o que geraria questionamentos de que, os atuais processos de valorizações simbólicas implicariam diretamente na performance, na recepção e/ou nas percepções do corpo.

Segundo Zumthor (2007 [1915]), a oralidade se restringe a dois momentos: a transmissão desencadeada pela voz e a recepção adquirida pela audição. Esse binômio formaria a performance; a leitura acabaria por restringir-se a decodificação de uma marca e/ou voltada para a informação. Sob tal ótica existiram várias formas de performance: a completa que envolve a visão geral dos fatos atrelada a audição dos mesmo contra a leitura solitária caracterizada pela falta de mediadores. Para Zumthor (2007 [1915], p. 50 e 51):

\begin{abstract}
A performance é então um momento de recepção: momento privilegiado, em que um enunciado é realmente recebido. (...) É verdade que a tecnologia de nosso século de algum modo perturbou o esquema que eu esboço assim: a introdução dos meios auditivos e audiovisuais, (...) modificou consideravelmente as condições da performance. Mas eu não creio que essas modificações tenham tocado na natureza própria desta.
\end{abstract}

Para Zumthor, a performance, a partir de um conceito antropológico se reporta ao ato da comunicação, algo existente no presente, um momento maior que o da recepção, que definira segundo os preceitos defendidos, como um processo que possui duração e que mede as desenvolturas praticadas pelo corpo. Nesse instante, agrega que a presença dos meios auditivos e audiovisuais alterou as condições da performance. Assim, o conceito de poesia defendido por Zumthor (2007, p. 12) como sendo "uma arte da linguagem humana, independente de seus modos de concretização" continua a valer, mas estaria vinculado a um pacote de serviços simbólicos que repercutem no afastamento social devido a essa quase que "obrigatoriedade" a uma vida virtual.

De qualquer forma, o repasse de tradições através de discursos sobre a relevância de determinados objetos e/o ações, tal como a defesa de ideias contrárias parte geralmente, do uso da oralidade; entretanto, esse processo foi empurrado inevitavelmente pelo desenvolvimento das tecnologias para um ambiente que representa novas concepções sociais. O conhecimento ou a percepção como classifica Santaella (2012) fica condicionado a 
capacidade de interpretação de leituras realizada pelo sujeito que utiliza os meios de comunicação, que no caso estudo se reporta aos meios virtuais.

E assim, o único ser vivo dotado da capacidade de fala e consequentemente capaz de atribuir valores as coisas que nomeia tem transferido na pós-modernidade, o foco dessa explanação sobre o processo de valorização simbólica segundo a visão da antropologia e dos estudos culturais, para o ponto da reconstrução de um perfil social de pessoas que fazem parte de práticas de trocas ou de compartilhamento que os colocam em um patamar de destaque ou de subalternidade no grupo do qual estão inseridos.

\section{CONSIDERAÇÕES FINAIS}

Atualmente, as leituras realizadas sobre o outro que está ao nosso lado, na expectativa provavelmente de entender a nós mesmos, se dá não apenas pela narração de atos físicos, mas principalmente a partir do local de fala do sujeito. Como já foi relatado no início do trabalho, o ser humano continua em um processo constante de reflexões sobre a posição que ocupa na sociedade, o papel que representa tal como sobre as contribuições que pode deixar para aqueles que estão chegando.

Ao compreender o homem como produto e não mais como produtor de significados tem-se a oportunidade de não apenas criticar a realidade da linguagem, mas através de um pensamento mais profundo emergir os sentidos que estão no entre-lugar do simbólico, na casa vazia. Um lugar onde a mobilidade dos objetos que se configura em encontros e desencontros, em um paradoxo que impulsiona ao não-sentido, a uma espécie de metade que não se completa, mas que permite reflexões para entender o simbólico.

O processo da oralidade ocorre através dos deslocamentos intrínsecos as emissões e recepções, performances e percepções da fala entre aqueles que se valem dela para a comunicação. Sendo assim, o que evidencio é uma inquietação por presenciar certas mudanças no comportamento social das pessoas que resultam no afastamento presencial desses indivíduos em troca do encontro virtual e impessoal, no qual as emoções são aguçadas pelo processo da visão e da leitura; a valorização empregada a esse meio de comunicação é cada vez maior.

Os estudos culturais ao propor o desmonte do indivíduo possibilitam remontar o repertório do sujeito em questão, livre de outros interesses que constam em seu discurso devido o contato direto com dispositivos de poder. Assim é possível contextualizar o ambiente estudo colocando no centro das discussões, aqueles que se encontravam nas margens 
literárias.

As contribuições de Cevasco e Williams possibilitam o entendimento de que os estudos sobre uma vertente cultural alicerçam transformações sociais que culminam nas intervenções políticas. Dessa forma entendo que o homem não deve ser caracterizado apenas pelas ações que pratica, mas também pelo contexto sob o qual está inserido tal como pelas construções sociais que desenvolve com os outros sujeitos ao seu lado.

O que se esperava com esse trabalho era uma diacronia de pensamentos que respondessem a inquietações derivadas do atual conceito vendido de mundo globalizado. A esfera capitalista, muito antes de plantar bases sólidas na sociedade, já apresentava seus primeiros acordes quando da segmentação social pelo princípio do ter ao invés do ser. $\mathrm{O}$ indivíduo que até então fora compreendido pela sua participação em um processo de repasse cultural, social, familiar e físico foi transportado para um espaço novo, recheado por significações derivadas de linguagens, sentidos e discursos contaminados por outros interesses.

A mudança na percepção de aplicabilidades de valor aos objetos abriu as portas para um mundo que prioriza sentidos rasamente definidos. Vivemos assim, o tempo do consumir e reproduzir sem pensar no papel representativo que desempenhamos. O que pesa como prática condição cultural, de postulação de um lugar nessa sociedade ainda pautada por conceitos fechados ainda é o acumulo de riquezas que geram valor e destaque perante aos demais do grupo.

Assim, o estudo da oralidade se apresenta quase como um trabalho etnográfico da voz, pois o prazer gerado pelas leituras se mostra como um sentimento mais forte, algo que transpõe a decodificação de signos analisáveis haja vista é através do corpo que ocorrem as manifestações dos sentimentos. As performances e recepções ganharam novas concepções, mas sem jamais perder espaço entre as relações interpessoais confirmando dessa forma que, toda memória adquirida pelo corpo, ou seja, a acumulação memorial se torna virtual e viceversa caracterizando um discurso poético; a pós-modernidade possibilita essas reflexões.

\section{REFERÊNCIAS}

AGAMBEN, Giorgio. O que é um dispositivo? In: O que é contemporâneo? E outros ensaios. Tradução: Vinícios Nicastro. Chapecó: Argos, 2009.

BHABHA, Homi K. O entre lugar das culturas. In: O bazar global e o clube dos cavaleiros ingleses. Traução: 
Tereza Dias Carneiro. Rio de Janeiro: Rocco, 2011.

CEVASCO, Maria Elisa. O tema "cultura e sociedade". In: CEVASCO, Maria Elisa. Dez lições sobre estudos culturais. São Paulo: Boitempo editorial, 2003.

DERRIDA, Jacques. Posições. Tradução: Tomaz Tadeu da Silva. Belo Horizonte: Autêntica, 2001.

GEERTZ, Clifford. Uma descrição densa. Por uma teoria interpretativa da cultura. In: GEERTZ, Clifford. A Interpretação das Culturas. Rio de Janeiro: LTC, 1989.

KUPER, Adam. Cultura, diferença e identidade. In: KUPER, Adam. Cultura. A visão dos antropólogos. Bauru: EDUSC, 2002.

SAHLINS, Marshall. La Pensée Bourgeoise. A sociedade ocidental enquanto cultura. In: SAHLINS, Marshall. Cultura e Razão Prática. Rio de Janeiro: Zahar Editores, 1979.

SANTAELLA, Lúcia. Culturas e artes do pós-humano: da cultura das mídias à cibercultura. São Paulo: Paulus, 2003.

SANTAELLA, Lúcia. Percepção: fenomenologia, ecologia, semiótica. São Paulo: Cengage Learning, 2012.

THOMPSON, John B. Capítulo III. O conceito de cultura. In: THOMPSON, John B. Ideologia e cultura moderna. Teoria social crítica na era dos meios de comunicação de massa. Petrópolis: Vozes, 1995.

ZUMTHOR, Paul. Introdução à poesia oral. Tradução: Jerusa Pires Ferreira, Maria Lúcia Diniz Pochat, Maria Inês de Almeida. Belo Horizonte: Editora UFMG, 2010.

ZUMTHOR, Paul. Performance, recepção, leitura. Tradução: Jerusa Pires Ferreira e Suely Fenerich. 2 ed. São Paulo: Cosac Naify, 2007, 128 p. 